\title{
REFLEXÕES SOBRE ESTADO E VIOLÊNCIA EM "A MONTANHA QUE DEVEMOS CONQUISTAR” DE ISTVÁN MÉSZÁROS
}

\author{
Antonio Marcondes dos Santos Pereira* \\ Eduardo F. Chagas ${ }^{* *}$
}

\begin{abstract}
RESUMO
O presente artigo tem como propósito precípuo desenvolver uma análise crítica acerca do livro do filósofo marxista húngaro István Mészáros "A montanha que devemos conquistar". Nesse sentido, buscamos evidenciar a problemática central da obra que trata das questões pertinentes às nossas contingências contemporâneas mais urgentes, principalmente no que tange aos limites da nossa ordem sociometabólica. O que para o autor constituem contingências globais, com todas as suas implicações para o planeta, não obstante, a destrutividade do capital imposta em larga escala sendo uma ameaça para toda a humanidade. A destruição em curso da natureza torna claro que há um limite para tudo, e os limites absolutos do capital demonstram que é insustentável a vigência dessa forma sociometabólica de existência. E aqui entra a função do Estado, que na sua estruturação, na base material antagônica do capital,tem como ação legítima proteger a ordem sociometabólica vigente. Sob tais condições histórico-sociais desencadeadas pela crise estrutural inalterável do capital, o Estado, diz o autor, se afirma e se impõe como a montanha que devemos conquistar, em todas as suas dimensões estruturais profundamente integradas.
\end{abstract}

\begin{abstract}
This paper's essential purpose is to develop a critical analysis on the Hungarian Marxist philosopher István Mészáros' book "The mountain we must conquer". In that sense, we seek to evidence the central issue of that work which deals with questions concerning our most urgent contemporary contingences, especially the one about the limits of our sociometabolic order. According to the author, those are global contingences, with all their implications to the planet, although the global destructibility enforced by capital in a large scale represents a threat to all humanity. The ongoing destruction of nature makes clear that there is a limit for everything, and the capital's absolute limits demonstrate that such form of sociometabolic existence is untenable. Here comes the function of State, which in its very structure, on the antagonistic material base of capital, has the duty of protect the existing sociometabolic order. Under such socio-historical conditions unleashed by the capital's unalterable structural crises, State, says the author, affirms and imposes itself as the mountain we must conquer, in all its deeply embedded structural dimensions.

\footnotetext{
*Graduado em História pela Faculdade de Educação, Ciências e Letras do Sertão Central - FECLESC da Universidade Estadual do Ceará -UECE; Mestre em educação pela UECE e Doutorando em Educação Brasileira-UFC. E-mail: antoniomarcondes_pereira@yahoo.com.br

${ }^{* *}$ Doutor em Filosofia pela Universität von Kassel (Alemanha); Professor da Graduação e da Pós-Graduação do Curso de Filosofia da Universidade Federal do Ceará (UFC) e Colaborador do Programa de Pós-Graduação da Faculdade de Educação (FACED) da UFC. Professor Bolsista-Pesquisador do CNPq. E-mail: ef.chagas@uol.com.br. Homepage: http://efchagasufc.wordpress.com/. Editor da Revista Dialectus (http://www.revistadialectus.ufc.br/index.php/RevistaDialectus/about/editorialPolicies\#sectionPolici es).C.V(Lates): http://lattes.cnpq.br/2479899457642563. (http://buscatextual.cnpq.br/buscatextual/visualizacv.do?id=K4794196Y0).
} 
No seu livro A montanha que devemos conquistar: reflexões acerca do Estado (2015), o filósofo marxista húngaro István Mészáros (1930-) desenvolveuma contundente crítica teórica acerca dos fundamentos histórico-conceituais do Estado.Sua reflexão busca evidenciar que o problema mais candente com o qual a humanidade hoje se depara é o da possibilidade concreta desuplantaçãodo Estado em sua totalidade orgânica, mediante uma tomada de posição político-social consciente, que vise à pose do Estado e sua consequente destruição ou, necessariamente, seu "fenecimento".

O Estado moderno ancorado sob as bases da ordem sociometabólica de reprodução material do capital, desempenha um papel determinante na "[...] totalidade das funções reprodutivas da sociedade, desde os processos produtivos matérias elementares até os domínios culturais mais mediados" (MÉSZÁROS, 2015, p. 16). Para Mészáros, portanto, a verdadeira questão reside no fato de que a própria natureza dos processos de tomada de decisão das formações estatais sob a égide do capital, historicamente constituídos, representa apenas um paradigma de "sobreposição alienada" e, por isso mesmo, só uma base sociometabólica "substancialmente diferente" pode significar concretamente a superação dos processos de tomada de decisão global da ordem social vigente.

As formações estatais do sistema do capital, fundadas em "determinações estruturais antagônicas", nunca seriam capazes de cumprir suas funções corretivas e de estabilizações requeridas, sem sobrepujar-se a todas as resistências encontradas como "um corpo alienado par excellence de tomada de decisão global" (MÉSZÁROS, 2015, p. 17). Nesse sentido, para o autor, longe de se constituir uma alguma "anarquia sem lei”, a alternativa socialista está fundamentalmente preocupada em defender uma concepção geral e a consolidação prática de um modo "qualitativamente diferente" de intercâmbio social.

A maior preocupação hoje é que, na prática,as leis instituídas pelas formações estatais do capital, na sua base materialmente antagônica de seus próprios microcosmos constitutivos sejam no âmbito local ou global, não podem funcionar e realmente não funcionam. Ela funciona, afirma Mészáros, "de fato", mas tão somente ao impor-se como "força", ou "lei do mais forte", emergindo e preponderando como uma determinação impositiva validada pelo Estado em contraposição a toda forma de relutância em potencial.

Todavia, a despeito de todas as investidas de "eternização" a-históricas do Estado, a imposição da "lei do mais forte" sobre o conjunto da sociedade não poder ser uma tônica 
constante. O momento crucial advém "quando os limites absolutos ${ }^{1}$ do sistema do capital são ativados em uma forma historicamente determinada, comprometendo a viabilidade das correções necessárias das formações estatais do sistema em todas as suas formas dadas e imagináveis" (MÉSZÁROS, 2015, p. 18).

Nessa polêmica sobre o Estado, constituído na base sociometabólica da reprodução material do capital, assevera István Mészáros:

[...]. Com efeito, os Estados do sistema do capital não são de forma alguma inteligíveis em e por si mesmos, mas apenas como complementaridade corretiva necessária para os defeitos estruturais de outras formas incontroláveis de seu modo orientado para a expansão da reprodução sociometabólica. E esse imperativo estrutural de expansão pode ser impulsionado pelo bem-sucedido processo de acumulação apenas durante o tempo em que ele puder prevalecer em seus termos materiais de referência confrontando a natureza sem destruir a própria humanidade [...]. Isso significa que os limites insuperáveis das formações estatais estabelecidas não residem simplesmente em um nível politicamente corrigível [...], mas nos limites absolutos do modo, em última instância, suicida com que o capital exerce o controle sociometabólico, ativado através da crise estrutural do sistema em geral. (MÉSZÁROS, 2015, p. 18-19, itálicos no original).

Nesse sentido, é oportuno reiterar que a oposição real, que deve ser constantemente ratificada, é entre a lei "autonomamente determinada" pelos sujeitos sociais em liberdade de associação em todos os âmbitos de suas vidas, desde as suas atividades produtivas mais concretas até as mais elevadas exigências regulatórias de seus processos de tomadas de decisões sociais e culturais gerais, e a lei "sobreposta” acima deles, “[...], por outro, através da codificação apologética da relação de forças estabelecida por um órgão independente, por mais "democrático" que esse órgão seja no sentido de legitimação do estado" (MÉSZÁROS, 2015, p. 19).

\footnotetext{
${ }^{1}$ Mészáros destaca no livro Para além do capital (2011) que esses limites absolutos são especificamente típicos apenas para o sistema do capital, devido às determinações mais penetrantes de seu modo de controle sociometabólico. E salienta a necessária reflexão de que: “[...], é preciso fazer a ressalva de que não devemos imaginar que o incansável impulso do capital de transcender seus limites deter-se-á de repente com a percepção racional de que agora o sistema atingiu seus limites absolutos. Ao contrário, o mais provável é que se tente tudo para lidar com as contradições que se intensificam, procurando ampliar a margem de manobra do sistema do capital em seus próprios limites estruturais [...]. Diante do fato de que a mais problemática das contradições gerais do sistema do capital é a existente entre a impossibilidade de impor restrições internas a seus constituintes econômicos e a necessidade atualmente inevitável de introduzir grandes restrições, qualquer esperança de encontrar uma saída desse círculo vicioso, nas circunstâncias marcadas pela ativação dos limites absolutos do capital, deve ser investida na dimensão política do sistema [...]. Igualmente, não pode haver dúvida de que o sucesso ou não desta ação corretiva (ajustada aos limites estruturais do sistema global do capital), apesar de seu caráter evidentemente autoritário e de sua destrutividade, vai depender da capacidade ou incapacidade da classe trabalhadora de rearticular o movimento socialista como empreendimento verdadeiramente internacional”. (MÉSZÁROS, 2011, p. 220).
}

\begin{tabular}{|l|l|l|l|l|}
\hline Gonista Dialectus & Ano 2 & n.7 & Setembro-Dezembro 2015 & p. 13-24 \\
\hline
\end{tabular}


Essas leis impostas pelo sistema do capital, com todas as suas modalidades coercitivas, só podem ser rechaçadas em razão de uma "ordem metabólica socialista substantivamente equitativa", fundada na forma de microcosmo produtivo no qual os sujeitos sociais possam, livremente, "definir a lei para si mesmos". Porém, a consecução dessa nova ordem só é concebível ao suplantar o capital do processo sociometabólico e extirpar, dessa maneira, "[...] a centrifugalidade das células constitutivas há muito estabelecidas do intercâmbio social” (MÉSZÁROS, 2015, p. 20).

As formações estatais do sistema do capital se apresentam atualmente muito perigosas. Dada a sua situação histórica contemporânea, baseada nessa "centrifugalidade antagônica" das células constitutivas do sociometabolismo produtivo estabelecido, onde a regulação por parte do Estado se torna um mecanismo de legitimação das determinações antagônicas mais profundas da sociedade. Só uma verdadeira "redefinição qualitativa" das atuais condições históricas, em um sentido praticamente sustentável, pode consubstanciar uma sociabilidade efetivamente equânime, erradicada do próprio capital, afirma Mészáros.

Os arautos da democracia representativa buscam reduzir as soluções dos problemas mais graves enfrentados hoje pela humanidade, à "igualdade formal" da lei, quando o que se configura na realidade objetiva é a mais evidente "falta de equidade substantiva" da dimensão política de regulação do Estado, e onde efetivamente elas não podem ser encontradas. Só há saída desse círculo vicioso autodestrutivo, diz o filósofo marxista, pela via do que ele chama de "democracia substantiva", na qual necessariamente prevalece uma autorrealizável regulação do modo de existência dos indivíduos, em condições sociais efetivamente construídas por processos sociometabólicos autodeterminados.

Na seara da história do pensamento político, Mészáros destaca que:

[...] descobrimos que a preocupação fundamental das teorias do Estado, debatidas de Platão e Aristóteles em diante, sempre esteve voltada para as diferentes formas em que as modalidades de tomada de decisão em geral com os seus benefícios ou suas desvantagens rivalizantes podiam ser elogiadas ou criticadas. Uma forma ou outra do Estado - ou das constituições concorrentes na visão de Aristóteles - foi sempre considerada como o modo necessário e abrangente de tomada de decisão [...]. Assim, também a esse respeito, podemos testemunhar uma mudança significativa por volta do século XVIII, quando o Estado como tal começou a se tornar o objeto de reflexão crítica, em contraste com o questionamento apenas dos méritos relativos às diferentes formas de o Estado sobrepor-se na vida social como árbitro último em todos os principais assuntos. (MÉSZÁROS, 2015, p. 23). 
No percurso dessa reflexão histórica, Mészáros ressalta que os processos revolucionários do final do século XVIII e do preâmbulo do século XIX trouxeram consigo não só um aumento da consciência de classe e dos antagonismos de classe, tal como do impacto de algumas grandes guerras entre os Estados constituídos, mas também a crise do processo político em si e a legitimação necessária de que as velhas maneiras de lidar com essas crises já não podiam ter funcionamento. Nesse sentido, a análise dessas condições sóciohistóricas, confrontou os principais teóricos da época coma questão quase impeditiva de abordar "a legitimidade ou não da própria lei”.

É com Hegel, de acordo com Mészáros, que surge a ideia de uma solução mais grandiosa para os problemas sociais, enunciada em plena concordância com sua perspectiva de classe burguesa, notadamente em sua obra A filosofia do direito. Mesmo reconhecendo os antagonismos sociais fundamentais de seu contexto histórico, Hegel reiterou com uma firmeza classista justificada, a legitimidade indubitável da lei. É nesse sentido, em termos gerais que, para Hegel, o Estado enquanto esfera superior da eticidade; da exteriorização do espírito absoluto e o lugar de realização das liberdades plenas superaria as carências e misérias próprias da sociedade civil.

Mészáros situa aqui o Liberalismo. Esta corrente de pensamento político-econômico que se apresentou no proscênio histórico no mesmo período das insurreições revolucionárias do final do século XVIII. O programa do Liberalismo sempre assumiu em relação à legislação e gestão social o status de representante legítimo do conjunto da sociedade. Suas proposituras, em geral, visavam instituir melhoramentos significativos, com o objetivo de dirimir os problemas em erupção e os conflitos da ebulição revolucionária, todavia sempre bem delimitado no quadro estrutural da ordem vigente, criticando-a apenas superficialmente.

Dessa forma o Liberalismo não tomava em consideração a dimensão histórica da constituição dos Estados nem tampouco sua legitimidade questionável representava qualquer problema. De forma mais direta, o Liberalismo foi caracterizado tanto pela "evasão sistemática dos fundamentos, incluindo a questão da legitimidade do processo legislativo além dos termos técnicos/processuais, quanto de uma forma positiva pela defesa de melhorias sociais e políticas ilimitadas, incluindo a extensão da concessão estruturalmente controlável para as eleições parlamentares”. (MÉSZÁROS, 2015, p. 24-25).

O Liberalismo, na concepção de Mészáros, nunca poderia estar a favor de uma sociedade "equitativa", mas apenas uma sociedade "mais equitativa", o que sempre representou "muito menos do que equitativa". Pois "o Liberalismo sempre fechou os olhos

\begin{tabular}{|l|l|l|l|l|}
\hline Qovista Qialectus & Ano 2 & n.7 & Setembro-Dezembro 2015 & p. $13-24$ \\
\hline
\end{tabular}


para o fato embaraçoso de que uma melhoria significativa visando uma sociedade equitativa só pode resultar de uma mudança fundamental na estrutura da própria produção". (MÉSZÁROS, 2015, p. 25).

O Estado, na sua estruturação na base material antagônica do capital, "não pode fazer outra coisa" auspiciar a ordem sociometabólica vigente, defendê-la custe o que custar, independentemente dos riscos para o futuro da sobrevivência da espécie humana. É exatamente nesse sentido, que para Mészáros isso representa o tamanho da montanha que não pode ser ignorado, ao tentarmos transformar positivamente nossas condições de existência. São estas as circunstâncias histórico-sociais que se desdobram da crise estrutural irreversível do capital, onde o Estado se afirma e se impõe como a "montanha que devemos escalar e conquistar".

O fato concreto é que, no modo de produção capitalista, a violência se torna um sintoma intrínseco a lógica de funcionamento do próprio sistema. Uma violência que perpassa o cotidiano e se expressa pelas formas mais aviltantes de exploração do trabalho e reprodução do capital: a prostituição, o desemprego, a miséria social, o analfabetismo, o trabalho de menores, a corrupção política, a exploração sexual infantil, o tráfico de drogas, as favelas, o vergonhoso e desumano sistema prisional (citamos aqui o caso do Brasil, que possui uma das maiores populações carcerárias do mundo em situação de precarização profunda), a opressão contra as mulheres, os pobres, os negros etc. Todos esses graves problemas produzidos pela sociedade capitalista são reproduzidos e perpetuados pela realidade política do Estado, que não consegue suplantar substantivamente essas condições sociais vigentes.

O sistema do capital é fundamentado em três esteios interligados: capital, trabalho e Estado. Nenhum deles pode ser abolido por si mesmo. As tipificações peculiares do capital e do trabalho assalariado em suas personificações historicamente dadas podem ser juridicamente eliminadas, e restituídas, "mas não o capital e o trabalho como tais", em seu aspecto mais substantivo de constituição como são encontrados na ordem sociometabólica capitalista. A verdade que deve ser lembrada, diz Mészáros, é que tudo que pode ser destruído também pode ser restituído. E até hoje isso foi feito, no que tange à vigência do Estado.

Nesse sentido assevera Mészáros que:

A materialidade do Estado está profundamente enraizada na base sociometabólica antagônica sobre a qual todas as formações de Estado do capital são erguidas. Ela é inseparável da materialidade substantiva tanto do capital quanto do trabalho. Só uma visão combinada de sua inter-relação 
tríplice torna inteligíveis as funções legitimadoras do Estado do sistema do capital. (MÉSZÁROS, 2015, p. 29).

Aqui, os problemas em evidência atualmente, no âmbito da tomada de decisão política global, como necessariamente gerenciado pelo Estado, não podem ser dirimidos sem fazer concessão à sua base sociometabólica mais intensa. Assim, fica claro que o sociometabolismo antagônico das classes sociais,que está na base das formações do Estado, constitui um entrave à plena realização de uma possível e concreta equidade social substantiva, não obstante, a totalidade das determinações estruturais do capitalconfrontar-se com a humanidade.

Os antagonismos estruturais profundos no cerne das contradições insuperáveis do Estado só podem ser abolidos, portanto, se forem colocados sob o controle de uma ordem social historicamente sustentável (Mészáros, 2015). E, aqui, vem à baila uma questão decisiva: o capitalismo pode perdurar ainda por muito tempo sem colocar em risco a existência da própria humanidade?

Para Mészáros, um dos problemas mais gritantes de nosso tempo é, certamente, a crise estrutural da política e as soluções propostas pelos Estados vigentes, pois:

[...] Para onde quer que olhemos e quaisquer soluções que nos sejam oferecidas, suas características definidoras comuns sempre mostram as contradições e as limitações dos Estados-nação historicamente constituídos. Esse é o caso também quando a justificativa utilizada para as políticas desenvolvidas está cheia da retórica da universalmente louvável "democracia" e da inevitável "globalização", atrelada à projeção de respostas em conformidade com tais determinações. Ao mesmo tempo, as soluções reivindicadas são, explícita ou implicitamente, sempre baseadas no pressuposto de que a alienação da tomada de decisão política em geral, há tempos historicamente estabelecida, materializada nos Estados modernos, deve manter-se permanentemente a única estrutura possível de gestão social em geral (MÉSZÁROS, 2015, p. 35, aspas no original).

Essa passagem sugere a crítica de Marx. Sua concepção acerca da necessária revolução socialista é, com toda clareza, indesligável de sua crítica ao "Estado enquanto tal", e não unicamente do Estado capitalista. Essa consideração crítica é manifestada por Marx, não só no que diz respeito à transformação radical do Estado vigente, mas de seu completo "fenecimento". Nesse sentido, Marx formulou uma reflexão sobre o Estado, fundamentalmente diferente até mesmo dos mais significativos pensadores burgueses.

No decurso do processo histórico da época moderna, os grandes pensadores da burguesia elaboraram duas obras, certamente, grandiosas acerca do Estado. Obras que demarcaram com profundidade de análise os fundamentos históricos e filosóficos do Estado e que, ainda hoje, são de uma atualidade evidente. São elas: o Leviatã de Thomas Hobbes, 
produzida em meados do século XVII, e Filosofia do Direito de Hegel, concebida na primeira metade do século XIX. Ambos estes autores não tinham nenhuma intenção nas proposições do liberalismo. Hegel teceu uma crítica ferrenha às ilusões liberais que, de forma falaciosa, transfiguraram a capacidade de consecução dos "privilégios parciais", preconizados pelos seus beneficiários (bem longe de possuírem um caráter universal), “em apelos totalmente insustentáveis à validade universal" (Mészáros, 2015).

É evidente que tanto Hobbes como Hegel formularam seus conceitos, demarcados por suas diferentes, ainda que muito fortes, idealizações do "Estado-nação", constituindo-se, nesse sentido, em evidentes teorizações burguesas do Estado. Especificamente em Hegel, o Estado se configura como o "reino da liberdade realizada". A liberdade fora do Estado é impossível para o filósofo alemão (não tendo em conta este como um aparato), mas sim como a totalidade dos sujeitos que o estruturam, os que juntos constituem o grande sujeito coletivo. Esse sujeito "é o mundo do espírito produzido a partir dele mesmo como uma segunda natureza". O sujeito como um ser natural/antinatural superou o seu estado natural e produzirá, portanto, uma segunda natureza, a que aparecerá como eticidade.

A realização plena da liberdade do indivíduo para Hegel vai ocorrer exatamente no Estado ético ${ }^{2}$. Momento de superação dos seres humanos e de todas as etapas da história, desde o direito, passando pela moral individual-subjetiva, para desembocar na eticidade, a esfera superior de todos os valores da humanidade configurada na arte, na religião e na filosofia.A grandeza do pensamento de Hegel sobre as questões mais importantes acerca dos problemas do Estado expressou-se, dessa maneira em seu modelo fundamental de proclamar “a relação orgânica entre a sociedade civil existente e o Estado ético projetado" (Mészáros, 2015, p. 77).

Dessa forma Hegel, na interpretação de Mészáros, pôde demarcar, diante dos antagonismos sociais que "ele teve de admitir e o fez", a solução proposta na forma de sua "representação sistêmica da realização contraditória do encerramento histórico", que colocou

\footnotetext{
${ }^{2}$ Outras formas de Estados realizados na história foram: “[...] O Estado absolutista: é a proposta da coerção que deve impor a ordem por meio da força. Acredita que os indivíduos da sociedade civil se encontram, como diz Hobbes, num estado de natureza, pré-social, no qual cada um vela por si mesmo e agride os outros. A única solução é um pacto mediante o qual absolutamente tudo seja entregue ao soberano, que, como grande Leviatã, mantenha todos em ordem. [...] O Estado liberal: é o Estado que não deve se imiscuir demais na sociedade civil, isto é, no campo econômico. Deve proteger a propriedade, ou seja, o mercado, e deixar que este se desenvolva de acordo com as suas próprias leis, pois é o encarregado de distribuir os bens e o faz com "uma mão invisível". É a proposta de Locke e Adam Smith. [...] O Estado democrático: é o Estado no qual o contrato é de todos com todos, mediante o qual se cria a vontade geral, a plena liberdade. Seus eixos são dois, o contrato e a religião, mas uma religião civil, sem dogmas que unam interiormente todos os indivíduos como verdadeiros cidadãos da pátria e não do céu. É a proposta de Rousseau" (RUBÉN, 2006, pp.214-215, itálico no original e negrito nosso).
}

\begin{tabular}{|l|l|l|l|l|l|}
\hline Revista & Dialectus & Ano 2 & n.7 & Setembro-Dezembro 2015 & p. $13-24$ \\
\hline
\end{tabular}


sob dúvida a legitimação da própria ordem social. Foi, nesse sentido, que Hegel estabeleceu conceitualmente uma linha de pensamento crítico decisivo de "demarcação histórica" original da virada do século XVIII para o XIX.

No entanto, afirma Mészáros:

[...], o encerramento histórico, objetivamente marcando o fim da ordem da classe exploradora em geral, não poderia "realizar-se" (uma das categorias explicativas utilizadas frequentemente de Hegel) por si só. Ele também estava gestando os imperativos objetivos de uma ordem qualitativamente diferente, assumindo a forma de um desconhecido desafio radical na história passada, e representando, também, as condições objetivas e subjetivas vitais de uma superação efetiva da ordem da classe exploradora como tal. [...] A era revolucionária qualitativa e radicalmente nova, colocando na agenda histórica, como condição necessária da emancipação do trabalho, a combinação inseparável desse imperativo com a emancipação de toda a humanidade, já estava lá, na época de Hegel. (MÉSZÁROS, 2015, p. 77).

Hegel, de forma consciente, buscou representar sua perspectiva sobre o passado de modo a transformar o presente que se processava. E, nesse sentido, o filósofo alemão apontou uma definição que se constituía no cumprimento do "absoluto da reconciliação autorrealizada do Espírito do mundo como eterno presente” desde seus primórdios (Mészáros, 2015).

As três dimensões da própria temporalidade foram transformadas em um “encerramento histórico" contínuo. E aqui também, Hegel reconheceu o presente eternizado da perspectiva saudosa da "coruja de Minerva", visualizada como a realização sintomática do desenlace histórico. Sobre essa questão Mészáros ressalta que:

A temporalidade hegeliana do Estado é fundamentada, em sua obra, pela noção do já mencionado "eternamente presente", que é, paradoxalmente, transfigurado em finalidade absoluta, graças ao ser de racionalidade em si "desde o início concluído", na forma do divino "Espírito do Mundo", evocativamente combinado por Hegel com a inquestionável e evidente autoridade mitológica da coruja de Minerva. Naturalmente, o agente real da história e do Estado nessa visão não poderia ser o ser humano autoconsciente. Tinha de ser o divino Espírito do Mundo, com sua "astúcia da razão". (MÉSZÁROS, 2015, p. 81).

Para Mészáros, a concepção de Estado de Hegel não tem sustentabilidade histórica e seu "canto de cisne" é resignante, pois seu apelo nostálgico à "coruja de Minerva" rechaça qualquer possibilidade de construção de um ordenamento estatal para além da ordem social do capital. A proposta conciliadora de Hegel entre o "racional e o real" (e a racionalidade do real) e o fato e a verdade constituída na autodivulgação da realização do "Espírito do mundo" como razão, ela mesma incorporada na ética do Estado, e aqui Mészáros mostra os limites da

\begin{tabular}{|l|l|l|l|l|}
\hline Govista & Ano 2 & n.7 & Setembro-Dezembro 2015 & p. $13-24$ \\
\hline
\end{tabular}


concepção do Estado de Hegel: sua sustentação baseada na "relação simbiótica" com a sociedade civil burguesa estabelecida, nisso está seu aspecto problemático.

Marx sempre preconizou com clareza que a possibilidade concreta de transformação histórica do futuro da humanidade é inconcebível sem o constante trabalho revolucionário fundamentado no que ele denominou de "organismo de crítica prática", isto é, a classe operária organizada internacionalmente, difundindo por meio das lutas sociais concretas seu programa revolucionário. E aqui se estabelece uma diferença fundamental entre a crítica de Marx do Estado e a concepção positiva do Estado em Hegel.

Mészáros também, nessa linha, tece uma reflexão crítica “à fórmula apologética” do Estado de Max Weber, que atribui o monopólio da violência legítima ao Estado (em muitos casos tido com uma ideia grandiosa), o que na verdade se constitui, segundo o próprio filósofo húngaro, numa pseudoexplicação epidérmica e um subterfúgio cínico do problema real em si.

Em Mészáros, portanto, a linha de crítica sobre essa questão se dá nos seguintes termos:

Isso está no mesmo nível de outra ideia profunda Weber, que grotescamente afirma que o Estado é a "criação de juristas ocidentais". Nenhuma das duas proposições tem sequer um valor explicativo mínimo relacionado às condições em que a formação do Estado moderno passa a existir e historicamente muda suas formas de instituição de medidas de consenso democráticas liberais em um determinado estágio de desenvolvimento para a adoção de regras francamente ditatoriais de controle. (MÉSZÁROS, 2015, p. $50)$.

E continua Mészáros enfatizando que a concepção de monopólio da violência legítima por parte do Estado se configura como graves problemas:

[...] referentes a por que o Estado deve recorrer à violência quando o faz e, ainda mais importante, até que ponto um sistema de gestão da sociedade como esse, exercido pelos processos de tomada de decisão política alienados, pode ser sustentado historicamente permanecem "mistérios" completos [...]. (MÉSZÁROS, 2015, p. 50).

Torna-se claro aqui que a concepção do Estado em Marx também difere significativamente da concepção de Weber. Marx concebe o Estado em termos estritamente negativos, porque, para o filósofo socialista alemão, o Estado enquanto tal deve ser suplantando. É, nesse sentido, que a concepção de política da modernidade em Marx deve ser circunscrita na esfera da negatividade. Pois, a característica principal da política democráticoburguesa para Marx é a de realizar as funções "destrutivas" do processo de transformação

\begin{tabular}{|c|c|c|c|c|}
\hline Revista Dialectus & Ano 2 & n.7 & Setembro - Dezembro 2015 & p. $13-24$ \\
\hline
\end{tabular}


social como: "a abolição da escravidão assalariada", "a expropriação dos capitalistas", "a dissolução dos parlamentos burgueses" entre outros.

Nessa concepção, Marx, como vai ressaltar Mészáros, conceituou a maneira de se tentar superar a relação complexa entre política e sociedade, sobrepujando conscientemente à revolução política sua dimensão social latente. Dai a célebre frase de Marx que enfatizava a legitimidade de uma "revolução política com uma alma social". E, para tanto, a derrocada do poder existente e a dissolução das antigas relações constituem um ato político revolucionário. Por isso, o socialismo não pode se efetivar sem um processo revolucionário concreto.

\section{CONCLUSÃO}

O sentido essencial da existência do Estado (moderno) é garantir a sustentabilidade sociometabólica da reprodução material do capital. Assim, podemos entender que a dominação do capital sobre o trabalho é de ordem econômica, e não política. Mas a política tem a função de garantir essa continuação da dominação material do capital, enraizada de forma estrutural. Afirma Mészáros que, por consequência, a dominação do capital não pode ser destruída no âmbito da política, mas apenas garantir sua organização formal.

Para Mészáros, a montanha que devemos conquistar parte desse esforço de compreensão de que o Estado é, em um sentido, "mediação por excelência”, pois articula a totalidade das relações internas da sociedade, da economia, da cultura, da justiça etc. e as incorpora também à estrutura global da organização social dominante. A tomada do poder do Estado mediante um processo emancipatório, com a finalidade de suprimi-lo, constitui um momento dialético fundamental de transição político-social para a consolidação da emancipação humano-social.

É elementar a preocupação de Mészáros com os limites atingidos pelo sistema de reprodução material do capital, o que põe em risco a sobrevivência da própria humanidade, não obstante a dominação e a destruição da natureza em curso. A necessidade e a urgência histórica da construção de uma outra ordem sociometabólica, pautada na organização social autodeterminada da produção material e o controle racional da riqueza socialmente construída é uma fim a ser buscado mediante uma tomada de decisão política radical e consciente. $\mathrm{O}$ anseio por constituir uma nova forma de organização político-social não pode passar pela reivindicação ideal de realização de um Estado formal, mas pela necessária construção concreta e historicamente viável da alternativa socialista.

\begin{tabular}{|c|c|c|c|c|}
\hline Rovista Dialectus & Ano 2 & n.7 & Setembro - Dezembro 2015 & p. $13-24$ \\
\hline
\end{tabular}


Portanto, é a viabilidade histórica e a sustentabilidade prática de uma alternativa real como o socialismo, que poderá tornar possível um modo de vida social pautado em princípios humanamente racionais. A consecução desse projeto histórico (a ordem autenticamente socialista) só poderá ser viabilizada, de acordo com Mészáros, sobre a "base material da apropriação racionalmente planejada" e condicionada do "trabalho excedente" produzido por todos os indivíduos associados livremente, e onde cada um em coletivamente possa realizar e satisfazer suas aspirações no seu tempo disponível, baseado em uma "igualdade substantiva" e no espírito de solidariedade.

\section{REFERÊNCIAS}

MÉSZÁROS, István. A montanha que devemos conquistar: reflexões acerca do Estado. São Paulo: Boitempo, 2015.

Boitempo, 2011.

Para além do capital: rumo a uma teoria da transição. São Paulo:

RUBÉN, R. Dri. A filosofia do Estado ético: a concepção hegeliana do Estado. In Filosofia política moderna: de Hobbes a Marx. (Org) BORON, Atilio A. Buenos Aires: Consejo Latinoamericano de Ciencias sociales - CLACSO; San Pablo: Depto. De Ciência Política FFLCH - Universidade de São Paulo, 2006.

\begin{tabular}{|c|c|c|c|c|}
\hline Q Rovista Oialeatus & Ano 2 & n.7 & Setembro - Dezembro 2015 & p. $13-24$ \\
\hline
\end{tabular}

